\title{
Consecuencias de las políticas de ajuste estructural en el sur de Europa
}

\author{
Consequences of structural adjustment \\ policies in southern Europe
}

\author{
José María García-Martínez \\ Universidad de Murcia, España \\ jm.garciamartinez@um.es \\ https://orcid.org/0000-0001-8992-0038
}

Recibido: 03/04/2021 Revisado: 31/05/2021 Aceptado: 18/06/2021 Publicado: 01/09/2021

\section{Resumen}

Este trabajo analiza los cambios operados en España e Italia en las primeras décadas del siglo XXI. Mediante un estudio transdisciplinar en ciencias sociales y el análisis de información recopilada en informes y bases de datos oficiales, se pretende reunir evidencia empírica de las transformaciones políticas operadas en los mercados de trabajo de ambos países a consecuencia de la difusión de la ideología neoliberal y la aplicación de políticas de ajuste estructural. El trabajo abarca tanto la implementación de políticas neoliberales desde finales de la década de 1980 como sus consecuencias sociales, intensificadas a partir de la segunda mitad de la década de 2010. Una de las principales conclusiones obtenidas en este estudio radica en que estas políticas monetaristas, aplicadas por los gobiernos nacionales bajo la batuta de instituciones como el Fondo Monetario Internacional, han conducido a un país como España a una grave situación donde la falta de empleos adecuados y las limitaciones políticas estructurales de acceso al empleo restringen gravemente las expectativas vitales para la mayoría de la población trabajadora, obligando a amplios sectores sociales a migrar a otros países. El artículo aborda las contradicciones entre las políticas neoliberales y las estructuras precapitalistas existentes en Italia y España, con el fin de plantear interrogantes que contribuyan a buscar alternativas políticas en favor de una mayor democratización social y económica.

\section{Palabras clave}

Desempleo, Europa, migración, corrupción, jóvenes, pobreza, neoliberalismo, crisis.

Forma sugerida de citar: García-Martínez, J. M. (2021). Consecuencias de las políticas de ajuste estructural en el sur de Europa. Universitas-XXI, 35, pp. 187-205. https:// doi.org/10.17163/uni.n35.2021.09 


\begin{abstract}
This paper analyzes the changes operated in Italy and Spain on the first decades of the $21^{\text {st }}$ century. Through a transdisciplinary study on social sciences and the analysis of statistical information compiled in reports and official databases, this article has the aim of gather empirical evidence of the political transformations occurred in both countries as a result of the spread of neoliberal ideology and the implementing of structural adjustment programs. This research comprehends the implementing of neoliberal policies from the decade of the 1980s as well as its social consequences, intensified since the second half of 2010s decade. One of the main conclusions found in this study lies in that the different policies conducted by national governments, under the aegis of Structural Adjustment Programs decreed by institutions such as the International Monetary Fund, drove an economy like Spain to a severe situation where the lack of adequate employment and the structural political constraints prevent a great part of workers from accessing to employment in fair conditions and critically restrict their life expectations, forcing ample sectors of the population to migrate abroad. The article tackles the contradictions between neoliberal policies and precapitalist structures existing in Italy and Spain, with the aim to outline questions that contribute to finding political alternatives in favor of greater social and economic democratization.
\end{abstract}

\title{
Keywords
}

Unemployment, Europe, migration, corruption, youth, poverty, neoliberalism, crisis.

\section{Introducción}

Las estadísticas del desempleo juvenil en España señalan que en 2019 afectaba a un 32,6 \% de la fuerza laboral entre 15 y 24 años. Estas elevadas cifras llegaron a situarse por encima de un $55 \%$ en el 2013 (St. Louis Fed, 2021a). De un total de 317000 ocupados a tiempo parcial entre 25 y 29 años registrados en el cuarto trimestre de 2020, más de 216000 jóvenes declararon que no habían podido encontrar un trabajo de jornada completa (Instituto Nacional de Estadística, 2021d). Más allá de atribuir de forma simplista la explicación de esta situación a las consecuencias de la pandemia de COVID-19, a la hora de analizar las causas y consecuencias del desempleo hemos de tener en cuenta las características estructurales del mercado de trabajo y las transformaciones sufridas en el mismo en el transcurso de la época de globalización neoliberal iniciada en la década de 1970. Diversos 
cambios legislativos han conducido a una reducción de los costes de contratación y al incremento de la "flexibilidad" de los trabajadores y trabajadoras. Siguiendo a Carrillo:

Persiste de forma obsesiva una tendencia a reemplazar el análisis científico de las causas subyacentes, el estudio del cambio histórico, por la simplicidad de discutir de forma tautológica sobre los síntomas que afloran constantemente en la superficie social, cuando realmente causas, síntomas y consecuencias deberían analizarse orgánicamente, como una unidad contradictoria. (Carrillo, 2020b, p. 148)

Muchos países de la periferia europea - como Grecia, Portugal, España y la Italia meridional - se caracterizan por unas elevadas cifras de desempleo. Las razones que explican estos problemas en el empleo no pueden considerarse únicamente desde un prisma cortoplacista, sino que su estudio debe insertarse en el contexto de la evolución histórica de estos territorios, atendiendo a su inserción en la gobernanza neoliberal de la Unión Europea bajo la moneda única. En palabras de Wolfgang Streeck, "un régimen monetario integrado para economías tan dispares como son un norte de Europa basado en la oferta y un sur basado en la demanda no puede funcionar igual de bien para ambas partes" (Streeck, 2017, p. 209).

El análisis de las consecuencias sociales de estas políticas en las estructuras locales puede arrojar luz acerca de cómo estos procesos globales repercuten en la vida cotidiana de las personas que residen en muchas regiones periféricas, y cómo unas estructuras políticas atrasadas se han mostrado en gran medida incapaces de dar solución a las demandas y necesidades de la mayoría de la población.

\section{Metodología}

En este artículo realizaremos un análisis de las transformaciones políticas que han tenido lugar en el contexto del sur de Europa a través de un enfoque transdisciplinar en ciencias sociales. Los cambios observados en los mercados de trabajo han sido en gran parte resultado de la aplicación de políticas de ajuste estructural por parte de los gobiernos y las instituciones supranacionales como el Fondo Monetario Internacional, consistentes en disminución de salarios, reducción del peso y la financiación del sector pú- 
blico, y cambios legislativos orientados a favorecer la inversión extranjera (Davis, 2006; Harvey, 2020).

Este análisis se ha llevado a cabo mediante una revisión bibliográfica de la investigación realizada en torno a la economía y sociedad de los países del sur de Europa. Este trabajo aborda estos problemas de forma dialéctica, valiéndonos de disciplinas científicas como la historia, la economía, la sociología y la geografía, junto con una lectura crítica de la información disponible en las bases de datos oficiales como el Instituto Nacional de Estadística español, Eurostat o la base de datos de St. Louis Fed. El estudio de estas fuentes junto con el análisis de la información obtenida en informes y bases de datos oficiales permite reunir evidencia empírica de las transformaciones sociales originadas en los mercados de trabajo de España e Italia, con el fin de contribuir a una mejor comprensión de los importantes cambios que han tenido lugar en las sociedades del sur de Europa en el siglo XXI, estudiando cómo estas políticas a favor del mercado han dado lugar a un importante deterioro de las condiciones de vida de la mayoría de la población de la Europa meridional.

\section{Análisis y resultados}

A la hora de estudiar un problema social como el desempleo, hay que tener en cuenta que afecta de forma desigual a la población joven que a las personas adultas. Ciertos sectores de trabajadores y trabajadoras, gracias a su experiencia, tienen la capacidad de reinsertarse en el mercado laboral. Sin embargo, concretamente en el caso de España, las condiciones estructurales de la economía y las exigencias de años de experiencia por parte de las empresas impiden a mucha gente joven iniciar su andadura en el mercado laboral dejándoles atrapados durante largos periodos de tiempo en el empleo informal. En un trabajo clásico, el sociólogo James Petras señaló los problemas que planteaba la transición del modelo desarrollista de la dictadura a la liberalización que tuvo lugar durante la presidencia de Felipe González (1982-1996) (Petras, 2018).

Es preciso analizar estos obstáculos estructurales que impiden el acceso de gran parte de los trabajadores y trabajadoras al empleo formal, como el arraigado clientelismo político en ciertas regiones, que impide el acceso igualitario a los empleos, favoreciendo a aquellos sectores de la población con conexiones familiares y de amistad con los estamentos políticos y eco- 
nómicos dominantes en un lugar determinado. Diversas investigaciones realizadas hace décadas han señalado la fuerza de los lazos familiares tradicionales en el sur de Europa (Narotzki, 1997). Wolfgang Streeck ha escrito que:

El sur italiano ilustra de manera ejemplar cómo los programas para el desarrollo regional pueden fracasar debido a circunstancias sociales y políticas (...) las ayudas para el desarrollo otorgadas por el Estado italiano fueron absorbidas por las estructuras locales de poder y utilizadas para consolidar las relaciones locales de dominación tradicional, caracterizadas por el clientelismo. (Streeck, 2016, p. 133)

Este hecho no deja de tener implicaciones políticas, ya que las clases dominantes propietarias de las grandes empresas y los medios de producción en estas regiones, junto a diversos sectores de trabajadores y trabajadoras estatales y agentes beneficiados por los procesos de crecimiento económico, tienen un evidente interés en la conservación de este statu quo, que permite a los colectivos beneficiados conservar su posición privilegiada en la estructura de estas sociedades, al tiempo que empuja al resto de la población a la migración forzada o la pobreza.

Las dinámicas de desarrollo desigual ocasionadas por la globalización neoliberal y la migración han afectado profundamente a una región periférica como Murcia (España). Este territorio local ha quedado inserto en la división internacional del trabajo creada en el contexto de la globalización contemporánea como una exportadora de materias primas, principalmente frutas y hortalizas, destinadas a los mercados mundiales. La aplicación de una serie de políticas de ajuste estructural por las clases dominantes nacionales y por los gobernantes locales ha conducido a importantes transformaciones tanto en la vida cotidiana como en los mercados laborales, que pueden observarse tanto en las nuevas dinámicas de desarrollo económico como en el mercado laboral y en la situación para el conjunto de la sociedad a partir de la segunda mitad de la década de 2010.

La región se ha rearticulado en la economía global como un territorio exportador de fuerza de trabajo (Delgado-Wise, 2013), tanto cualificada como no cualificada, que no puede encontrar un encuadre adecuado en la estructura económica de la región. La acumulación de capital se sostiene en una elevada extracción de valor excedente del trabajo realizado por migrantes procedentes del norte de África, de América Latina y de otros países europeos como Rumanía, así como en actividades relacionadas con el 
turismo, la hostelería y el sector de los juegos de azar, lo que ha conducido a protestas de jóvenes murcianos, un colectivo considerablemente afectado por estas políticas que privilegian la obtención de beneficios económicos en detrimento de la salud (Peñalver, 2019).

La población nacida en el extranjero y censada en 2020 en la región es de 253683 personas (Instituto Nacional de Estadística, 2020), una cifra que, sin embargo, no refleja la totalidad del colectivo, en concreto a aquellas personas que por diversas razones no hayan podido o querido realizar este trámite administrativo. Muchos de estos trabajadores y trabajadoras son indocumentados/as que no disponen de libertad para ejercer muchos de sus derechos (Schierup et al., 2018) y se ven forzados a aceptar condiciones de precariedad tanto en los empleos como en las viviendas donde residen, con frecuencia en pisos antiguos y en condiciones de hacinamiento, o no pueden denunciar los problemas que afrontan en la relación diaria con sus empleadores, en muchas ocasiones realizando trabajos de una importante peligrosidad y esfuerzo físico.

Los reducidos sueldos que perciben los trabajadores y las trabajadoras migrantes en Murcia, empleados en el sector agroindustrial, son un reflejo de estas relaciones laborales desfavorables para la población migrante que reside en la región (Calvo, 2020). Al desempleo característico de entornos donde la producción se basa en la extracción y venta de materias primas se añade la pérdida de empleos adicional ocasionada en países que se especializan en exportación de servicios como el turismo, buscando los ingresos procedentes de los turistas de zonas más prósperas como Alemania, Francia, Estados Unidos y Canadá. Un "síndrome holandés" adicional observado por José Gabriel Palma explica la persistencia del elevado desempleo en estos lugares (Palma, 2019). Es importante recordar, con Carrillo, que estamos lejos de que esto sea una "maldición de los recursos naturales", sino que "se trata de una premeditada conducción de la política económica" (Carrillo, 2018, p. 184).

Esta emigración de población, en muchos casos con elevadas cualificaciones sufragadas por los estados y los contribuyentes de la periferia europea, son contratados por empresas intensivas en capital en los países del Norte, como los ingenieros y bioquímicos españoles que trabajan en las grandes industrias químicas y de fabricación de automóviles localizadas en Alemania, quienes obtienen una mano de obra cualificada y con elevada productividad por la que no han debido invertir en su formación, lo que supone "nuevas modalidades de intercambio desigual” (Delgado-Wise, 2013, p. 30). 
A principios del siglo XX Antonio Gramsci ya advirtió sobre las condiciones que impedían a la Italia meridional lograr un desarrollo económico que beneficiase al conjunto de su población, debido a las características estructurales del proceso de desarrollo capitalista en el sur de Italia y a la resistencia de importantes intelectuales orgánicos que contribuían a extender una persistente hegemonía favorable al estado de cosas, como la iglesia en el siglo XIX. El análisis de Gramsci reveló que "en el territorio nacional se quedan los viejos, las mujeres, los niños y los inválidos, es decir, la parte de población pasiva que grava sobre la población trabajadora" (Gramsci, 2013, p. 158). La presencia de intelectuales orgánicos favorables al statu quo, que puede observarse en muchas sociedades de la periferia, es analizada por García-Bonafe, quien escribió que:

Desde el punto de vista de la función social, el intelectual meridional refleja la atrasada estructura agraria y encuentra en la administración estatal y local y no en la industria, una válvula de escape, viniendo así a ejercitar la función de intermediario entre el campesino y la administración en general y convirtiéndose así en un factor decisivo de contención de la presión campesina. (García-Bonafe, 1975, p. 290)

Estos factores contribuyen a que se extienda una "hegemonía", tal como la denominó Gramsci, que en dosis alternativas de consentimiento (el sentido común creado y extendido por los medios de comunicación y por gran parte de la misma población) y coacción (mediante las diferentes normativas y la legislación, respaldada por el poder del Estado) busca conseguir una aceptación del orden establecido entre la mayoría de la población (Gramsci, 2013, p. 370).

La captura de los mecanismos de la administración y del poder local por parte de los estamentos dominantes no se limita únicamente al mercado de trabajo, sino que también puede observarse en el proceso de vacunación contra el coronavirus, donde en regiones como Murcia y Extremadura se ha privilegiado la vacunación de altos cargos (Agencia EFE, 2021), lo que supone un atropello democrático frente al conjunto de la población, dado que no se ha tenido en cuenta a los colectivos más débiles y perjudicados, como ancianos, ancianas, trabajadores y trabajadoras de la sanidad. El gobierno murciano se ha limitado a crear las condiciones para que prosiga el proceso de desarrollo económico que favorece a los empresarios y empresarias más prominentes, así como a los propietarios y propietarias de capital, 
y no ha realizado una correcta distribución de los beneficios del crecimiento económico.

Las explosivas contradicciones experimentadas en la política española en 2021 a consecuencia de la moción de censura planteada por la oposición contra el gobernante Partido Popular, que ha ejercido una completa hegemonía durante décadas en la región murciana, ha llevado a la compra de varios políticos de la oposición mediante el otorgamiento de cargos y otros privilegios, ante las perspectivas de que la moción de censura condujera a un cambio de gobierno que pusiera en riesgo las estructuras clientelares de dominación presentes en la región. La captura de los mejores puestos de trabajo y los habituales lazos entretejidos entre el establishment político y económico, las empresas más prósperas en estos entornos locales, como las conserveras y las empresas de fabricación de productos agropecuarios, y los representantes políticos favorables a las demandas de los empresarios y empresarias y de la población más privilegiada impiden a muchos trabajadores y trabajadoras encontrar puestos de trabajo decentes y los empuja a diferentes formas de migración forzada o, en casos más graves, a la enfermedad mental y a la mendicidad. Un 37,2 \% de la población de la región de Murcia se encontraba en situación de pobreza en 2014, una cifra que se redujo a $27,7 \%$ en el 2019, principalmente por el importante movimiento migratorio que ha llevado a gran parte de la población al extranjero, para trabajar tanto en empleos cualificados (aquellos que cuenten con titulaciones universitarias) como en trabajos que no requieren cualificación universitaria. Una buena muestra de las consecuencias sociales ocasionadas por las políticas de ajuste estructural podemos observarla en el drástico incremento de la migración forzada a partir de la crisis sistémica ocurrida en 2008. La estadística de población española residente en el extranjero registra que el número de murcianos y murcianas que viven fuera de España se ha duplicado, pasando de unas veinte mil personas en 2009 a más de 44 mil en 2021, lo que no significa que este sea el número total, ya que es posible que muchas personas que trabajan en el extranjero no hayan realizado el trámite de inscripción (Instituto Nacional de Estadística, 2021a; 2021b).

La legislación inspirada por la ideología neoliberal, como la reforma laboral promulgada por el Partido Popular en el año 2012, destinada a reducir las cargas por cotizaciones del sector empresarial ha tenido efectos contraproducentes: sin ningún tipo de normativa que impida estas prácticas, deja a las empresas con total libertad para buscar unos menores costes salariales 
contratando a trabajadores y trabajadoras residentes en las proximidades de los centros de trabajo, lo que elimina la necesidad de pagar a los empleados y empleadas un sueldo que les permita alquilar una vivienda o una habitación, ya que los costes de reproducción social son afrontados por el trabajo de sus familias; o recurriendo a la contratación de los desempleados y desempleadas que estén registrados en las oficinas de empleo, seleccionando únicamente a aquellos trabajadores y trabajadoras que dispongan de certificados oficiales de discapacidad. La libertad de las empresas de aprovechar las bonificaciones a la Seguridad Social a través de estos modelos de contratación deja a muchas personas sin apenas opciones para poder trabajar. Para entender esta irracionalidad hemos de tener en cuenta, como escribió Hobsbawm, que "la elección racional de las empresas que solo buscan su propio beneficio consiste en: a) reducir al máximo el número de sus empleados, ya que las personas resultan más caras que los ordenadores, y b) recortar los impuestos de la seguridad social (o cualquier otro tipo de impuestos) tanto como sea posible" (Hobsbawm, 2012, pp. 565-566), sin tener en cuenta otras consideraciones de carácter más social.

A la "desregulación" del mercado de trabajo, entendida como la supresión o modificación de regulaciones estatales que protegen a los trabajadores y a las trabajadoras con el fin de atender a los requerimientos del capital de una fuerza de trabajo más flexible y con menores salarios, se une el crecimiento del "estado policial global" en palabras de William Robinson, por lo que el funcionamiento mismo del sistema deja muy pocas opciones a la gran mayoría de la población (Robinson, 2014).

Hemos de tener en cuenta las diversas medidas tomadas por los gobiernos españoles de PP y PSOE en las últimas décadas, desde la sanción constitucional al pago de la deuda externa durante la etapa de Rodríguez Zapatero (2004-2011), la reforma laboral del 2012 ya mencionada y la promulgación de la Ley de Seguridad Ciudadana en el 2015, conocida popularmente como Ley Mordaza, por el gobierno encabezado por Mariano Rajoy (2011-2018), junto con los sucesivos programas de ajuste estructural aplicados por los gobiernos nacionales bajo la batuta del Fondo Monetario Internacional y con el beneplácito de la canciller Angela Merkel (Fontana, 2013). El individualismo extremo instigado por la contrarrevolución cultural neoliberal (Carrillo, 2018) no deja ninguna alternativa de ayuda a la población más desamparada salvo los debilitados servicios públicos y las instituciones sociales creadas por los propios ciudadanos, tanto religiosas como civiles, muy deterioradas 
tras años de recortes de impuestos, y las débiles relaciones precapitalistas, como la familia, que todavía sostienen la reproducción social de muchas personas, reemplazadas muchas de ellas por relaciones capitalistas (pensemos en el cuidado de los nietos y nietas por parte de los abuelos y abuelas en el caso de las trabajadoras que recurren a sus parientes, mientras que muchas otras familias optan por la contratación asalariada de mujeres migrantes con salarios bajos para estas tareas de reproducción social, o a invertir en la compra, en muchas ocasiones financiada a crédito, de adelantos tecnológicos destinados a ahorrar trabajo en el hogar, como las aspiradoras robot, los robots de cocina, etcétera). Importantes cambios han tenido lugar en las esferas de la producción y la reproducción social que requieren ser analizados (Katz, 2001).

El recurso al crédito (Carrillo, 2020a) sostiene en gran medida el consumo en las economías contemporáneas, dado que la reducción de los salarios y el desempleo impiden a muchas familias tener suficientes ingresos para la compra, lo que también perjudica al crecimiento económico de estas regiones. Una muestra de la irracionalidad de las políticas de ajuste neoliberales en su pretendido objetivo de impulsar el crecimiento económico.

El sector público, particularmente la contratación en las instituciones públicas como las universidades, experimenta importantes problemas debido a las exigencias de certificaciones y las limitaciones características de una "universidad feudal" en palabras de Gonzalo Pontón (Nerín, 2019), que solo permiten iniciar su andadura laboral a aquellos con contactos en la universidad, arrojando al resto al desempleo y al mundo de la economía informal, que se ha incrementado dramáticamente a consecuencia de factores políticos como la desaparición del poder de los sindicatos. El resultado es una fuerza laboral universitaria afectada por una grave temporalidad, donde proliferan los contratos de sustitución y con sueldos que en muchas ocasiones no superan los 500 euros (Sánchez, 2021).

Podemos señalar, a modo de ejemplo de las consecuencias sociales de estas políticas, los requisitos de muchas empresas de traspasar los costes de seguridad social al Estado y a los propios trabajadores a través de la figura del falso autónomo, o la exigencia por parte de muchos empresarios y empresarias de que las personas trabajadoras aporten su propio portátil al comenzar el trabajo, con lo que supone para el desgaste de esta herramienta, un desgaste que no corre a cuenta del capitalista. Recordando la clásica fórmula del valor de la mercancía Capital Constante + Capital Variable + Plusvalor 
(Harvey, 2018), llegamos a una situación en la que el empresario o empresaria apenas aporta ningún capital constante para producir el bien o el servicio, solo un reducido capital variable en forma de salarios, y la población trabajadora se ve obligada a aportar el capital fijo necesario para desarrollar la actividad, junto con su fuerza de trabajo, que es la que crea el plusvalor que queda en poder de la empresa. Pese a toda esta apariencia de "autonomía", quien realiza el trabajo es el profesional autónomo que cobrará el importe recibido de la empresa, muchas veces en forma de factura, lo que significa que el valor excedente quedará en poder de la empresa a quien le ofrece sus servicios, libre de soportar cargas de seguridad social (Mesas, 2021).

Todo esto ha dado lugar a novedosas formas de contratación informal. La extensión contemporánea de las nuevas tecnologías hace posible que una empresa en China disponga de trabajadores y trabajadoras falsos autónomos en España, que crearán un mayor valor con su trabajo sin necesidad de que la empresa aporte ningún tipo de capital, ni siquiera el ordenador en el que ha de realizarse la actividad laboral. Las aplicaciones de mensajería instantánea permiten a los empresarios y empresarias en otros países controlar cualquier aspecto en el desempeño del trabajo y asignar tareas a sus empleados y empleadas en cualquier momento. Como ejemplo de estos cambios en las relaciones de producción, podemos señalar que a diferencia del tradicional repartidor de pizzería que entrega en un ciclomotor propiedad de la empresa, los riders o repartidores de plataformas como Glovo aportan su propio capital fijo que permitirá llevar a cabo la actividad (ya que trabajan con sus propios smartphones y bicicletas). Una investigación revela que "las plataformas a menudo fijan el precio del servicio y definen los términos y condiciones del servicio, o permiten a los clientes definir los términos (pero no a los trabajadores)" (Berg \& De Stefano, 2017, s.p.).

La parte más débil de esta relación también se ve afectada en su formación, ya que "la responsabilidad para poner al día constantemente sus habilidades recae en el trabajador independiente, que tiene menos acceso a formación y un conocimiento imperfecto de las habilidades necesarias que se requieren para el progreso" (Escobari \& Fernandez, 2018, s.p.). Estos trabajadores pierden ingresos debido a la amortización de estos medios de producción necesarios para llevar a cabo su actividad, mientras que la empresa intermediaria (ya sea de transporte de comida o de enseñanza de idiomas) recibe un considerable porcentaje en concepto de ingresos rentistas. Como señala Carrillo: 
$\mathrm{Al}$ actuar como meros intermediarios laborales, gracias a su prodigiosa innovación app, pueden llegar a percibir el $20 \%$ de las transacciones realizadas, a veces incluso más. ¿Podríamos denominar a dicha forma de extracción de renta con el término deliberadamente ambiguo de economía colaborativa? (Carrillo, 2020a, p. 88)

No solo hay que tener en cuenta esta pérdida de ingresos, sino que "incluso cuando los trabajos ocupan un periodo de algunas horas o algunos días, el trabajador necesita estar constantemente buscando nuevo trabajo". No obstante lo anterior, los autores advierten que "muchos ya estaban trabajando siete días a la semana y el $50 \%$ indicaban que habían trabajado por más de diez horas durante al menos un día en el mes pasado" (Berg \& De Stefano, 2017, s.p.). Christian Fuchs ha señalado que:

Un ingreso básico garantizado financiado por impuestos al capital que garantice un salario vital puede empoderar a los trabajadores asalariados y a las trabajadoras domésticas: las asalariadas pueden rechazar trabajos que son en algún sentido precarios, lo que empodera su posición frente al capital. (Fuchs, 2018, s.p.)

En palabras de Chris Hedges:

El capitalismo corporativo está estableciendo una servidumbre neofeudal en numerosas ocupaciones, una condición en la que no hay leyes laborales, no hay salario mínimo, no hay seguridad social y no hay regulaciones. Trabajadores desesperados y empobrecidos, obligados a aguantar jornadas de 16 horas, son agresivamente enfrentados unos con otros. (Hedges, 2018, s.p.)

Como ha señalado Mike Davis, una de las particularidades de los mercados de trabajo informales es la "involución urbana", esto es, la obligación que tienen muchos trabajadores y trabajadoras de trabajar aún más horas dada la ingente oferta de titulados y tituladas existente, obligándoles por efecto de la competencia a trabajar más duramente o reducir los precios por hora que piden a los que contratan sus servicios (Davis, 2006, pp. 182-183).

Muchos de estos trabajos se realizan sin ningún contrato ni respaldo por parte de la seguridad social, siendo la única garantía para el colectivo de jóvenes trabajadores y trabajadoras informales la buena fe en que los que los contratan cumplirán su parte del acuerdo, lo que no siempre ocurre. Esta situación, que afecta tanto a los desempleados autóctonos y a las desemplea- 
das autóctonas como a la población migrante, permite a las empresas, propietarios y propietarias de capital que lo requieren el acceso a una fuerza de trabajo extremadamente adaptable y dócil, sin capacidad de negociación, sin contrato ni seguridad social, y que no tendrá posibilidad de elegir para sujetarse a las demandas de aquellos que los contraten. De este modo este colectivo de clase trabajadora sujeto a un desempleo estructural, y en muchos casos agravado por su falta de documentación de residencia, queda en situación de indefensión, expuestos en muchos casos a extorsiones y prácticas reprobables por parte de otros agentes sin escrúpulos, convirtiéndose en una masa de trabajadores y trabajadoras sin derechos de la que colectivos más prósperos pueden beneficiarse. Un informe de la Organización Internacional del Trabajo ha revelado que "más del 85 por ciento de los trabajadores en España tienen un trabajo temporal porque les fue imposible encontrar un empleo permanente" (ILO, 2019, p. 50).

Los problemas que plantea el desempleo a largo plazo son bien conocidos. Como advierte Fontana:

Perder el trabajo, algo que puede suceder fácilmente en las actuales condiciones de indefensión laboral, puede significar el inicio de un largo calvario, ya que el paro a largo plazo tiende a perpetuarse, porque los que buscan trabajadores discriminan a este tipo de parados, culpándoles por su inactividad. (Fontana, 2017, p. 602)

El desempleo no solo afecta a los ingresos, sino también al bienestar psicológico de las personas trabajadoras y sus familias (Petras, 2003; Davies, 2011). No es difícil imaginar que la situación ocasionada por el COVID-19 y los confinamientos incremente la violencia, las tensiones y otros problemas en el interior de los núcleos familiares, al ser confinados muchos trabajadores informales y muchos desempleados y desempleadas. La falta de empleos y de ingresos ocasionada por la crisis económica es probable que incremente el malestar y conduzca a resultados dramáticos, como el incremento de la violencia de género dentro de los hogares, al no disponer estas familias de ninguna alternativa por parte del Estado salvo limitados subsidios como el ingreso mínimo vital, que requieren complejos trámites para ser solicitados. 


\section{A modo de conclusión}

Una de las razones del elevado desempleo y los importantes niveles de migración forzada en regiones periféricas como Murcia se encuentra en los obstáculos estructurales presentes en su economía y las limitaciones de su sistema productivo. David Harvey ha señalado, estudiando el caso de Grecia, que las "economías de baja productividad intensivas en fuerza de trabajo", como son aquellas economías donde no hay elevadas inversiones de capital fijo ni una producción de bienes y servicios con elevado valor añadido, como avanzados bienes tecnológicos, se sostienen en la contratación de una fuerza de trabajo de bajos salarios y en los beneficios que esta pueda proporcionar, por lo que la tasa de beneficios de los empresarios y empresarias no es muy elevada, pese a que se extraiga un importante valor excedente de estos trabajadores y trabajadoras (ya sea porque trabajen muchas horas o porque cobren salarios muy bajos). Como escribe Harvey:

El problema para Grecia es que tienen un régimen de trabajo de baja productividad. Y esto significa que no importa lo duro que trabajen, la mayoría del valor que ellos crean va a ser absorbido a Alemania por mecanismos de mercado libre que tienden a igualar la tasa de beneficio. (Harvey, 2020, p. 169)

Sería necesario transformarse en una economía intensiva en capital como Alemania, un objetivo complicado cuando las mismas reglas de la Unión Europea, la moneda única y las instituciones del Fondo Monetario Internacional limitan los radios de acción de los gobiernos nacionales, recomendando bajar los salarios para mejorar la "productividad de la economía española", esto es, crear incentivos para que los empresarios inviertan a través de unos menores costes salariales.

Las bases de datos oficiales nos ofrecen información que permiten evidenciar este deterioro de las condiciones de trabajo para el conjunto de la población. De acuerdo con las estadísticas, el salario bruto mensual para el decil de población más empobrecido disminuyó de un salario medio de 495,94 euros en 2009 a 411,17 euros en 2014, encontrándose en 2017 por debajo de los niveles de 2009, con 464,34 euros de salario medio. El decil 2 también experimentó una reducción de un salario medio de 875,93 euros al mes en 2009 a 819,61 euros en 2014. Por el contrario, el decil más rico de la población aumentó sus ingresos de una media de 4370,12 euros de salario bruto mensual en 2009 a 4616,94 euros en 2014 (Instituto Nacional de 
Estadística, 2021c). Las estadísticas de Eurostat, por su parte, muestran que mientras los costes laborales (esto es, los salarios) aumentaron de 19,4 euros en 2008 a 22,8 euros en 2020 en España y de 25,2 euros a 29,8 euros en Italia, en Francia estos costes aumentaron de 31,2 euros a 37,5 euros, y en Alemania se incrementaron de 27,9 euros a 36,6 euros en el mismo periodo (Eurostat, 2021).

Esta "devaluación interna" que implica el estancamiento o la reducción de los salarios ha conducido a la transformación de muchos países en "exportadores de fuerza de trabajo", tanto de forma directa mediante la migración como de forma indirecta a través de la inversión extranjera, atraída por unos menores costes laborales (Delgado-Wise, 2020). Tal y como explica Michael Hudson:

La emigración implica una pérdida del capital que se ha invertido en criar, educar y formar a una mano de obra que se ve obligada a emigrar en busca de trabajo. Lo que ahora está llevando a la mano de obra europea a la emigración es la severa política de deuda. (Hudson, 2018, p. 437)

La información recopilada por St. Louis Fed señala que la deuda de los hogares españoles se incrementó de un 59,7 \% del PIB en 2002 a un 85,6\% del PIB en 2006, disminuyendo a un 61,6 \% en 2019 (St. Louis Fed, 2020). Este incremento puede explicarse por el aumento de créditos a los hogares para la adquisición de vivienda mediante la contratación de hipotecas, que condujeron a amplios sectores de población y a muchas empresas a endeudarse irresponsablemente. Sin embargo, no hay que olvidar que gran parte de la deuda española ha tenido como origen la socialización de las pérdidas del sector privado, como muestra el hecho de que la deuda pública se situara en 67,5 \% del PIB en 1996, disminuyendo a 35,8 \% del PIB en 2007 y, tras las políticas neoliberales de rescate del sector bancario en 2008 comenzara un vertiginoso proceso de endeudamiento que alcanzó el 100,7 \% del PIB en 2014 (St. Louis Fed, 2021c).

La reducida inversión en I+D no permite contar con grandes empresas que produzcan vacunas u otros bienes necesarios para convertirse en una economía intensiva en capital. Como ya hemos apuntado, José Gabriel Palma ha estudiado los problemas que plantea el "síndrome holandés", el importante incremento del desempleo, adicional al desempleo ocasionado por la desindustrialización en curso desde finales del siglo XX y el traslado de las inversiones en fábricas a otros países, que tiene lugar cuando un país ex- 
perimenta un superávit en servicios como el turismo, en contraste con buscar un superávit en la producción de manufacturas, que incorporan mayor valor añadido. Para clarificarlo, baste señalar el precio al que se vende un smartphone o un ordenador portátil producidos en Corea del Sur al precio al que puede venderse un menú en un restaurante o un frasco de agua de colonia producidos en España.

David Harvey denuncia:

La rápida degradación de la calidad de la vida urbana, como consecuencia de los desahucios, la persistencia de prácticas depredadoras en el mercado de la vivienda, las reducciones de servicios y sobre todo la falta de oportunidades viables de empleo en los mercados laborales urbanos. (Harvey, 2018, p. 363)

Las estadísticas muestran un incremento de los precios desde 2015, así como un espectacular crecimiento del desempleo entre 2007 y 2013 (St. Louis Fed, 2021b; 2021d). La encuesta de población activa revela una severa disminución del número de población asalariada entre 25 y 29 años con contrato indefinido, de un millón y medio de trabajadores y trabajadoras registrados en el segundo trimestre de 2007 a 767300 en el segundo trimestre de 2017. La población asalariada con contrato temporal en esta franja de edad, por su parte, aumentó de 624200 personas en el cuarto trimestre de 2013 a 746800 asalariados y asalariadas temporales en el cuarto trimestre de 2019 (Instituto Nacional de Estadística, 2021e).

\section{Gráfico 1}

\section{Trabajadores y trabajadoras asalariados entre 25-29 años, España}

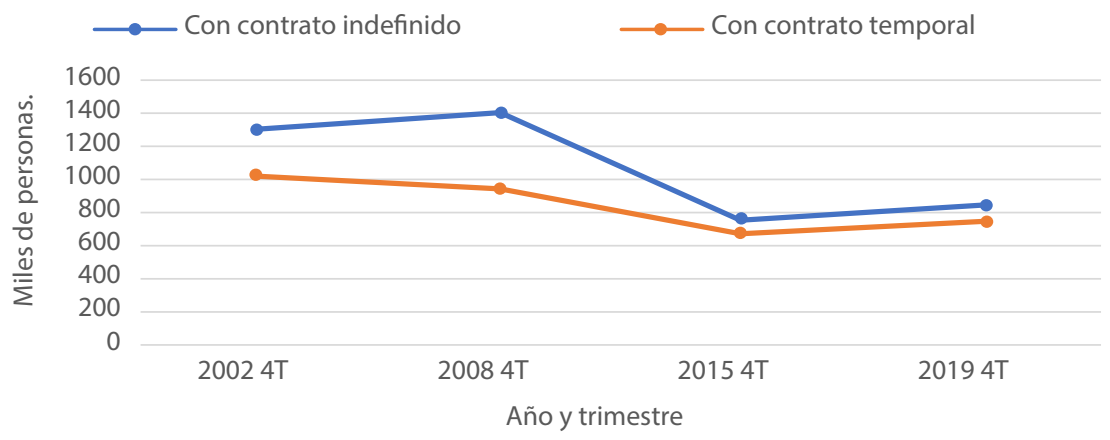

Fuente: Elaboración propia con datos de INE. 
Estas cifras revelan el importante deterioro social y económico originado por las políticas inspiradas en la ideología neoliberal aplicadas desde finales de la década de 1980, lo que una vez entrados en la tercera década del siglo XXI han configurado un mercado de trabajo precario y sin apenas oportunidades laborales para la gente joven. Este tipo de cuestiones requieren importantes replanteamientos si el objetivo es buscar alternativas de futuro para el importante número de personas desempleadas y con contratos precarios que viven en la periferia europea, con el fin de lograr cambios fundamentales y transformar este statu quo desfavorable para la mayoría de trabajadores, trabajadoras y pequeños empresarios y empresarias.

\section{Agradecimientos}

Quiero agradecer a mis profesores Germán Carrillo, Carmen Cerdá y Juan Ortín (Universidad de Murcia) por su ayuda y sus valiosas observaciones.

\section{Bibliografía}

Agencia EFE (12 de febrero de 2021). Hay altos cargos en la lista de vacunados en Murcia, según diputados que la ven. https://bit.ly/31Qa6Kp

Berg, J., \& De Stefano, V. (18 de abril de 2017). It's time to regulate the gig economy. OpenDemocracy. https://bit.ly/2QY5ZcU

Calvo, E. (16 de diciembre de 2020). Los migrantes explotados en una nave del Campo de Cartagena y rescatados de un zulo: "Creíamos que íbamos a morir allí dentro". Eldiario.es. https://bit.ly/3wktDR9

Carrillo, G. (2018). La desintegración civil del demos moderno. Intersticios, 12(2), 5-23. https://bit.ly/3fzSzO8

Carrillo, G. (2020a). La era de la irracionalidad política global. Migración y Desarrollo, 18(34), 57-113. https://bit.ly/3wMnWLe

Carrillo, G. (2020b). Transgresiones de la Historia. Pasajes, 60, 117-151. https:// bit.ly/3fDQ0ux

Davies, W. (2011). La economía política de la infelicidad. New Left Review, 71, 59-73. Davis, M. (2006). Planet of slums. Verso.

Delgado-Wise, R. (2013). The Migration and Labor question today: Imperialism, Unequal Development and Forced Migration. Monthly Review, 64(9), 25-38. https://doi.org/10.14452/MR-064-09-2013-02_3 
Delgado-Wise, R. (2020). Replanteando la cuestión del desarrollo y su relación dialéctica con la exportación de fuerza de trabajo de cara al siglo XXI. Migración y Desarrollo, 19(35), 7-24.

Escobari, M., \& Fernandez, S. (19 de julio de 2018). Measuring American gig workers its difficult, but essential. Brookings. https://brook.gs/3cG7K71

Eurostat (2021). Labour cost levels by NACE Rev. 2 activity.

Fontana, J. (2013). El futuro es un país extraño. Pasado y Presente.

Fontana, J. (2017). El siglo de la revolución. Pasado y Presente.

Fuchs, C. (2018). Capitalism, Patriarchy, Slavery and Racism in the age of Digital Capitalism and Digital Labour. Critical Sociology, 44(4-5), 677-702. https://dx.doi.org/10.1177/0896920517691108

García-Bonafe, M. (1975). Gramsci y la cuestión meridional. Estudis: Revista de Historia Moderna, 4, 277-291. https://bit.ly/3sFQTqk

Gramsci, A. (2013). Antología de Manuel Sacristán. Akal.

Harvey, D. (2018). Marx, Capital and the Madness of economic reason. Oxford University Press.

Harvey, D. (2020). The Anti-Capitalist Chronicles. Pluto Press.

Hedges, C. (25 de marzo de 2018). 'The Gig Economy' is the new term for serfdom. Truthdig. https://bit.ly/3sHJzuq

Hobsbawm, E. (2012). Historia del siglo XX. Crítica.

Hudson, M. (2018). Matar al huésped. Capitán Swing.

Instituto Nacional de Estadística (2020). Estadística del Padrón continuo.

Instituto Nacional de Estadística (2021a). Estadística del Padrón de españoles residentes en el extranjero.

Instituto Nacional de Estadística (2021b). Encuesta de condiciones de vida.

Instituto Nacional de Estadística (2021c). Salario bruto mensual del empleo principal. Limites inferiores y valores medios de cada decil.

Instituto Nacional de Estadística (2021d). Ocupados a tiempo parcial por motivo de la jornada parcial, sexo y grupo de edad.

Instituto Nacional de Estadística (2021e). Asalariados por tipo de contrato o relación laboral, sexo y grupo de edad.

International Labor Organization (2019). World Employment and Social Outlook: Trends 2019. ILO.

Katz, C. (2001). Vagabond Capitalism and the Necessity of Social Reproduction. Antipode, 33(4), 709-728. https://doi.org/10.1111/1467-8330.00207

Mesas, A. (5 de febrero de 2021). Paro, precariedad y constante incertidumbre: el retrato de una generación perdida. El Salto. https://bit.ly/31EQWqt 
Narotzki, S. (1997). 'Cultura', 'Región' y trabajo en la vega baja del Segura. Trabajo, Revista Andaluza de Relaciones Laborales, 3, 89-107.

Nerín, G. (22 de octubre de 2019). Gonzalo Pontón: "Quizás no quieren que la gente aprenda". elnacional.cat. https://bit.ly/31AiCwT

Palma, J. G. (2019). Desindustrialización, desindustrialización "prematura” y "síndrome holandés”. El Trimestre Económico, 86(344), 901-966. https:// doi.org/10.20430/ete.v86i344.970

Peñalver, V. (21 de marzo de 2019). Los alumnos de un instituto de Murcia declaran la guerra a las casas de apuestas: "Ponéis en peligro a los jóvenes". Eldiario.es. https://bit.ly/3fxGwkb

Petras, J. (2003). Neoliberalismo, Resistencia popular y salud mental. Barbecho, Revista de Reflexión Socioeducativa, 2, 13-16. https://bit.ly/2SD59TH

Petras, J. (2018). Padres-hijos: Dos generaciones de trabajadores españoles. Encrucijadas. Revista crítica de ciencias sociales, 15, 1-29. https://bit. ly/3pa1Vn0

Robinson, W. (2014). Global Capitalism and the crisis of humanity. Cambridge University Press.

Sánchez, A. (19 de marzo de 2021). La UPCT, única universidad en la Región que cumple con todos los criterios de calidad del Ministerio. La Opinión de Murcia. https://bit.ly/3rHhuCe

Schierup, C. U., Likić-Brborić, B., Delgado-Wise, R., \& Toksöz, G. (2018). Migration, civil society and global governance: an introduction to the special issue. Globalizations, 15(6), 733-745. https://doi.org/10.1080/14747731 .2018 .1503840

St. Louis Fed (2 de noviembre de 2020). Household Debt to GDP for Spain. https:// bit.ly/3wKN7xu

St. Louis Fed (19 de febrero de 2021a). Youth Unemployment Rate for Spain. https:// bit.ly/2SKCn $3 \mathrm{~m}$

St. Louis Fed (16 de marzo de 2021b). Harmonized Unemployment Rate: Total: All Persons for Spain. https://bit.ly/3ubsjxZ

St. Louis Fed (6 de abril de 2021c). General government gross debt for Spain. https://bit.ly/3p2S1mQ

St. Louis Fed (12 de mayo de 2021d). Consumer Price Index: All Items for Spain. https://bit.ly/34w3Dp9

Streeck, W. (2016). Comprando tiempo. Katz.

Streeck, W. (2017). ¿Cómo terminará el capitalismo? Traficantes de Sueños. 